\title{
Universiteit
}

Leiden

The Netherlands

\section{Rapidly maturing fentanyl clearance in preterm neonates}

Völler, S.; Flint, R.B.; Andriessen, P.; Allegaert, K.; Zimmermann, L.J.I.; Liem, K.D.; ... ;

Knibbe, C.A.J.

\section{Citation}

Völler, S., Flint, R. B., Andriessen, P., Allegaert, K., Zimmermann, L. J. I., Liem, K. D., ... Knibbe, C. A. J. (2019). Rapidly maturing fentanyl clearance in preterm neonates. Archives Of Disease In Childhood. Fetal And Neonatal Edition, 104(6), F598-F603.

doi:10.1136/archdischild-2018-315920

Version: $\quad$ Publisher's Version

License: $\quad$ Licensed under Article 25fa Copyright Act/Law (Amendment Taverne)

Downloaded from: https://hdl.handle.net/1887/3200413

Note: To cite this publication please use the final published version (if applicable). 


\section{Rapidly maturing fentanyl clearance in preterm neonates}

\author{
Swantje Völler, ${ }^{1}$ Robert B Flint, ${ }^{2,3,4}$ Peter Andriessen, ${ }^{5}$ Karel Allegaert 이, ${ }^{6}$ \\ Luc J I Zimmermann, ${ }^{7}$ Kian D Liem, ${ }^{8}$ Birgit C P Koch, ${ }^{4}$ Sinno H P Simons, ${ }^{2}$ \\ Catherijne A J Knibbe, ${ }^{1,9}$ DINO study group
}

- Additional material is published online only. To view please visit the journal online (http://dx.doi.org/10.1136/ archdischild-2018-315920).

For numbered affiliations see end of article.

\section{Correspondence to}

Dr. Swantje Völler, Division of Pharmacology, Division Systems Pharmacology and Biomedicine, Leiden Academic Centre for Drug Research, Leiden University, Leiden 2300 RA, The Netherlands;

s.voller@lacdr.leidenuniv.nl

SV and RBF contributed equally.

Received 24 July 2018 Revised 10 December 2018 Accepted 31 December 2018 Published Online First 1 February 2019

\begin{abstract}
Background Fentanyl is frequently used off-label in preterm newborns. Due to very limited pharmacokinetic and pharmacodynamic data, fentanyl dosing is mostly based on bodyweight. This study describes the maturation of the pharmacokinetics in preterm neonates born before 32 weeks of gestation.

Methods 442 plasma samples from 98 preterm neonates (median gestational age: 26.9 (range 23.9-31.9) weeks, postnatal age: 3 (range 0-68) days, bodyweight 1.00 (range $0.39-2.37$ ) kg) were collected in an opportunistic trial and fentanyl plasma levels were determined. NONMEM V.7.3 was used to develop a population pharmacokinetic model and to perform simulations.
\end{abstract}

Results Fentanyl pharmacokinetics was best described by a two-compartment model. A pronounced non-linear influence of postnatal and gestational age on clearance was identified. Clearance (L/hour/kg) increased threefold, 1.3-fold and 1.01-fold in the first, second and third weeks of life, respectively. In addition, clearance (L/ hour $/ \mathrm{kg}$ ) was 1.4-fold and 1.7-fold higher in case of a gestational age of 28 and 31 weeks, respectively, compared with 25 weeks. Volume of distribution changed linearly with bodyweight and was $8.7 \mathrm{~L} / \mathrm{kg}$. To achieve similar exposure across the entire population, a continuous infusion ( $\mu \mathrm{g} / \mathrm{kg} / \mathrm{hour}$ ) dose should be reduced by $50 \%$ and $25 \%$ in preterm neonates with a postnatal age of $0-4$ days and 5-9 days in comparison to 10 days and older.

Conclusion Because of low clearance, bodyweightbased dosages may result in fentanyl accumulation in neonates with the lowest postnatal and gestational ages which may require dose reduction. Together with additional information on the pharmacodynamics, the results of this study can be used to guide dosing.

\section{INTRODUCTION}

The treatment of preterm infants is related to an impressively high frequency of painful procedures and to periods of severe prolonged pain. ${ }^{1}$ It is crucial to protect hospitalised preterm neonates from pain for ethical reasons but also with regard to possible negative short-term and long-term consequences of untreated pain. ${ }^{23} \mathrm{~A}$ number of studies have shown that early stress and pain may influence the developing brain and thereby neurodevelopment, and change the stress and pain response later in life. ${ }^{34}$

Although pain is a major stressor in preterm infants, ${ }^{5}$ the discussion on how to adequately treat

\section{What is already known on this topic?}

It is crucial to protect preterm neonates from pain for ethical reasons but also to prevent possible negative short-term and long-term consequences of untreated pain.

- Pain is most likely undertreated in preterm neonates due to the lack of pharmacokinetic and pharmacodynamic data, especially in the youngest preterm infants.

- Fentanyl is an opioid used off-label in preterm infants for the relief of severe pain and it seems effective in this population.

\section{What this study adds?}

- Fentanyl clearance in preterm neonates increases with gestational as well as with postnatal age, reflecting both intrauterine and extrauterine maturation, respectively.

- Fentanyl clearance is very low during the first days of life which can lead to accumulation of the drug.

- Bodyweight-based fentanyl dose needs to be reduced during the first days of life to achieve comparable exposure across all preterm infants.

pain is ongoing. ${ }^{6}$ Pain assessment is extremely difficult and often inaccurate. ${ }^{8}$ Due to this and to the fear of potential side effects of analgesics, pain remains likely undertreated in preterm neonates. ${ }^{1}$ One of the most important reasons is that pharmacokinetic (PK) and pharmacodynamic data are still lacking, especially in the youngest preterm neonates.

Fentanyl is an opioid that is used off-label in neonatal intensive care units (NICU) for the relief of severe procedural and prolonged pain. It seems effective in preterm infants ${ }^{8}$ but data on the effect of fentanyl on pain scores are sparse and heterogeneous. While Guinsburg et al reported reduced physiological and behavioural pain scores in 22 neonates after single dose administration, ${ }^{9}$ Ancora et al only saw a significant reduction of premature infant pain profile scores during the first 3 days of a 7-day continuous fentanyl infusion in 67 neonates. $^{10}$

Data on the PK of fentanyl in preterm infants born before 32 weeks of gestation are sparse ${ }^{1112}$ 
Table 1 Characteristics (median (range)) of fentanyl patients included into the DINO study $(n=98)$

\begin{tabular}{ll}
\hline & Patient data \\
\hline Gestational age (weeks) & $26.9(23.9-31.9)$ \\
\hline Birth weight (g) & $906(390-1905)$ \\
\hline Postnatal age (at first fentanyl dose) (days) & $3(0-68)$ \\
\hline Duration on study* (days) & $3(1-80)$ \\
\hline Actual bodyweight (g) & $1000(390-2370)$ \\
\hline Indication for fentanyl administration (number of patients) \\
\hline \multicolumn{1}{l}{ Preintubation } & 28 \\
\hline Analgosedation & 43 \\
\hline Preintubation and analgosedation & 27 \\
\hline
\end{tabular}

* Defined as the time between the first and the last blood samples contributing to the analysis of fentanyl.

DINO, Drug dosage Improvement in Neonates

while few studies report on term neonates. ${ }^{13-15}$ In adults, fentanyl is mainly cleared by hepatic biotransformation via cytochrome P450 (CYP) 3A4. ${ }^{16-18}$ In neonates, this enzyme is known to show much lower activity, while its activity rapidly increases to values comparable to those in adults during the first weeks of life. ${ }^{19}$

Population PK and pharmacodynamic modelling has increasingly been applied to data from preterm infants as this advanced statistical approach can efficiently handle sparse and infrequently collected data. ${ }^{20} 21$ Besides quantifying PK parameters, it offers the possibility to quantify interindividual variability and to identify factors driving the PK, so-called covariates such as weight or postnatal age (PNA), and can thereby be used to optimise drug dosing. 2223

Within a multicentre study in four NICUs in the Netherlands, we prospectively collected data on fentanyl dosages and plasma levels during routine care using scavenge sampling. These were used to develop a population PK model in which the influence of covariates was studied, and to subsequently evaluate different dosing regimens across the age range of this special population.

\section{METHODS}

Data/study

The Drug dosage Improvement in Neonates (DINO) study (NL47409.078.14, MEC-2014-067, NCT02421068) prospectively studied a total of nine drugs, including fentanyl, in preterm infants born before 32 weeks of gestation in four different centres in the Netherlands. DINO aimed to develop evidence-based individualised dosing regimen for commonly used off-label drugs in preterm neonates. From September 2014 to July 2017, a total of 442 plasma samples from 98 neonates (42 female, 56 male) containing fentanyl were available for analysis (table 1). These neonates received 776 fentanyl doses either as bolus ( $\mathrm{n}=504$, median: $2.1 \mu \mathrm{g} / \mathrm{kg}$, IQR: $1.49-3.70 \mu \mathrm{g} / \mathrm{kg}$ ) or as continuous infusion ( $\mathrm{n}=272$, median: $1.0 \mu \mathrm{g} / \mathrm{kg} /$ hour, IQR: $0.998-2.00 \mu \mathrm{g} / \mathrm{kg} / \mathrm{hour}$ ) preintubation or for continuous analgosedation (table 1).

\section{Bioanalytical analysis, population PK analysis and model evaluation}

Fentanyl was quantified using an liquid chromatography-tandem mass spectrometry assay developed in the Department of Pharmacy at the Erasmus Medical Center in Rotterdam. ${ }^{24}$ Concentration measurements below the lower limit of quantification (14.9\% of the concentrations) were reported by the laboratory and used in the analysis.
The population PK analysis was performed using NONMEM V.7.3 (ICON Development Solutions, Ellicott City, MD, USA), supported by Perl-speaks-NONMEM (PsN) V.3.4.2 and Xpose V.4.3.5. ${ }^{25}$ Model development was performed in four steps: (1) selection of a structural model, (2) selection of an error model, (3) covariate analysis, and (4) internal validation of the model. The first-order conditional estimation with interaction method was used throughout model development. In case of missing covariate information, the last value observed in the subject was carried forward. For bodyweight, linear interpolation between available measurements was performed. The objective function value (OFV) was used to compare models, while a lower OFV indicated a better fit of the model to the data. A drop in OFV of more than 3.8 was considered statistically significant $(p<0.05)$ for structural model selection. SEs obtained from NONMEM and the CIs of the bootstrap analysis in PsN $(n=1000)$ were used to evaluate the precision of the estimated parameters.

The covariates birth weight, actual bodyweight, gestational age (GA), PNA, postmenstrual age and gender were evaluated using a stepwise covariate modelling procedure ${ }^{26}$ testing linear, exponential and power functions. A significance level of $p \leq 0.01$ was used for the forward inclusion and a significance level of $\mathrm{p} \leq 0.001$ for the backward elimination.

Key models as well as the final model were evaluated using goodness-of-fit plots and normalised prediction distribution errors ${ }^{27}$ based on 1000 simulations of the model and a bootstrap analysis based on 1000 samples of the data. More information on the internal validation is supplied in online supplementary material 1.

\section{Evaluation of different dosing regimens}

Using the final model 1000 simulations of typical dosing regimen were performed for three hypothetical preterm neonates with a birth weight of $0.75,1$ and $1.5 \mathrm{~kg}$ and a GA of 25,28 and 31 weeks, respectively. The weight of these neonates was simulated to develop according to the preterm growth curves published by Anchieta et al. ${ }^{28}$ Both bolus doses and continuous infusions were evaluated according to clinical practice at the time of the study. For the bolus dose, a single bolus dose of $2 \mu \mathrm{g} / \mathrm{kg}$ was administered at PNA days 1, 10, 20 and 30. For the infusion, a continuous infusion of $1 \mu \mathrm{g} / \mathrm{kg} /$ hour starting on PNA days $1,10,20$ and 30 was administered over a duration of 10 days with doses being adjusted to the changing bodyweight of the patient. As no target concentration has yet been defined for fentanyl in preterm neonates, different dose regimens were evaluated for their ability to achieve comparable exposure (eg, steady-state concentrations) across infants with different GA and PNA.

\section{RESULTS}

\section{Population PK analysis and model evaluation}

PNA and GA were found as best predictors for clearance within the context of a two-compartment model $(\mathrm{p}<0.001$ (116 points in OFV) and $\mathrm{p}<0.001$ (46 points in OFV), respectively). The combination of these two covariates was superior to postmenstrual age $(\mathrm{p}<0.001)$. Bodyweight was identified as best predictor for volume of distribution $(\mathrm{p}<0.001,49$ points in OFV). No other covariates were found.

Figure 1 shows how clearance changes with PNA for a newborn with a GA of 25,28 and 31 weeks with clearance expressed in $\mathrm{L} /$ hour in figure $1 \mathrm{~A}$ and in $\mathrm{L} /$ hour/ $\mathrm{kg}$ in figure $1 \mathrm{~B}$ (lines). The figure shows that the observed individual clearance values (dots) are in good agreement with the model (line) (figure 1). 

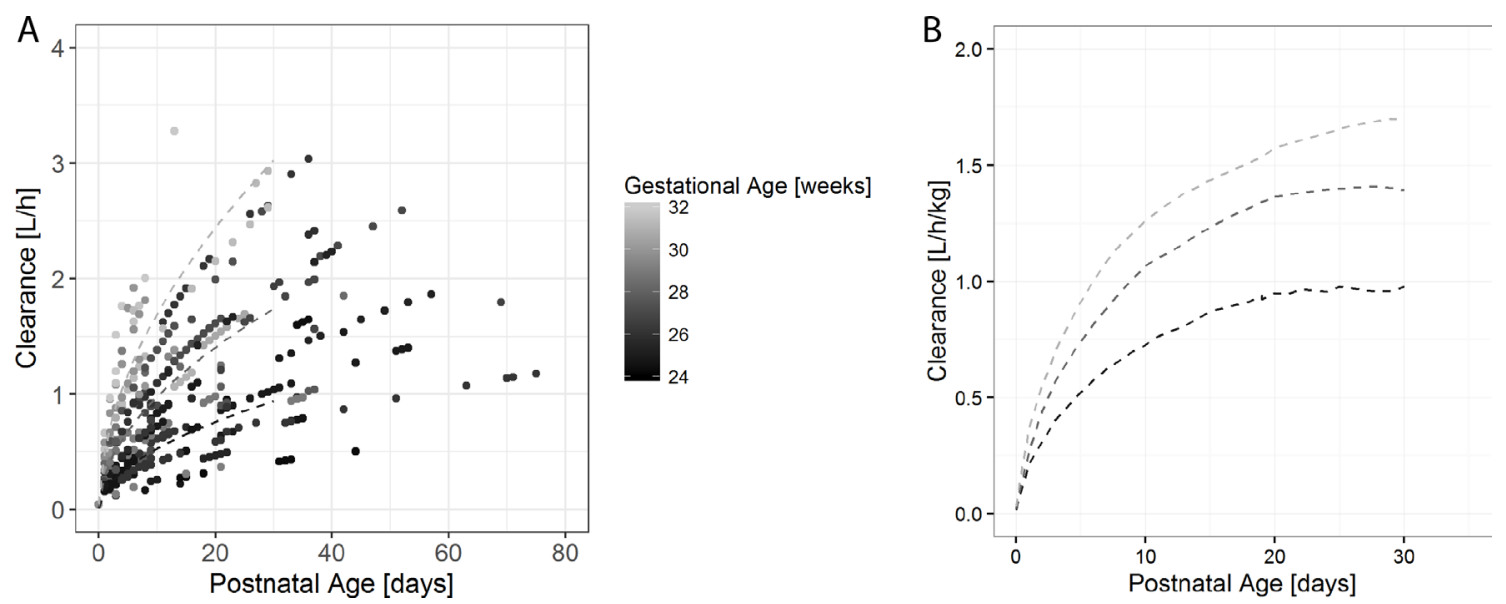

Figure 1 (A) Clearance (L/hour) versus postnatal age (days), depicted as population values (dashed lines) for children with a gestational age of 25 , 28 and 31 weeks, and individual post hoc clearance (CL) values (dots). (B) Clearance (L/hour/kg) versus postnatal age (days), depicted as population values (dashed lines) for children with a gestational age of 25,28 and 31 weeks.

The parameter estimates and their respective bootstrap estimates are provided in table 2. Figure 2 shows the goodness-of-fit plots of the final model. Model evaluation showed no trends towards a model misspecification and no other remaining trends with respect to time, concentration, GA or PNA (online supplementary material 1).

\section{Evaluation of different dosing regimens}

Figure 3 illustrates how concentration time profiles of preterm neonates change with different GA and PNA, when dosed according to their bodyweight. Figure $3 \mathrm{~A}$ shows that for a bolus dose $(2 \mu \mathrm{g} / \mathrm{kg})$, median maximal plasma concentrations are comparable in all age groups and around $0.25 \mu \mathrm{g} / \mathrm{L}$. However,

\begin{tabular}{|c|c|c|}
\hline Parameter & $\begin{array}{l}\text { Final model: } \\
\text { estimate } \\
\text { (RSE \%) }\end{array}$ & Bootstrap estimate $(95 \% \mathrm{Cl})$ \\
\hline \multicolumn{3}{|l|}{ Fixed effects } \\
\hline $\mathrm{CL}(\mathrm{L} /$ hour $)=\mathrm{CL}_{\mathrm{p}}$ & $0.415(8)$ & $0.413(0.337$ to 0.489$)$ \\
\hline \multicolumn{3}{|c|}{$\mathrm{CL}_{\mathrm{i}}=\mathrm{CL}_{\mathrm{p}}^{*}(\mathrm{PNA} / \mathrm{median} \mathrm{PNA})^{\mathrm{OPNA*}}(\mathrm{GA} / \mathrm{median} \mathrm{GA})^{\mathrm{OGA}}$} \\
\hline $\begin{array}{l}\Theta_{\text {PNA }} \text { (exponent for influence } \\
\text { of PNA on CL) }\end{array}$ & $0.528(11)$ & 0.534 (0.418 to 0.661$)$ \\
\hline $\begin{array}{l}\Theta_{G A} \text { (exponent for influence } \\
\text { of } G A \text { on } C L \text { ) }\end{array}$ & $5.43(13)$ & 5.34 (3.90 to 6.74$)$ \\
\hline$V_{1}(L)=V_{1 p}$ & $8.68(13)$ & 8.75 (6.56 to 11.18$)$ \\
\hline \multicolumn{3}{|l|}{$\mathrm{V}_{1 \mathrm{i}}=\mathrm{V}_{1 \mathrm{p}}{ }^{*}(\mathrm{WT} / \mathrm{i}$ median WT $)$} \\
\hline Q (L/hour) & $0.533(41)$ & $0.775(0.163$ to 3.00$)$ \\
\hline $\mathrm{V}_{2}(\mathrm{~L})$ & $3.15(23)$ & $3.30(1.90$ to 4.86$)$ \\
\hline \multicolumn{3}{|l|}{ Interindividual variability (eta) } \\
\hline On CL (\%) & $45.7(8)$ & $45.0(37.3$ to 52.2$)$ \\
\hline On V (\%) & $59.5(14)$ & 60.6 (37.4 to 79.4$)$ \\
\hline \multicolumn{3}{|l|}{ Residual variability } \\
\hline Proportional (\%) & $12.6(15)$ & 12.5 (8.85 to 16.9$)$ \\
\hline Additive $(\mu \mathrm{g} / \mathrm{L})$ & $0.0368(19)$ & $0.0341(0.0125$ to 0.0481$)$ \\
\hline
\end{tabular}

$\mathrm{CL}$, clearance; GA, gestational age (median GA, 26.9 weeks); $\mathrm{GA}_{\mathrm{i}}$, individual GA; $p$, population mean value of a parameter for an individual with PNA of 5 days and BW of $1 \mathrm{~kg}$ and a gestational age of 26.9 weeks; PNA, postnatal age (median PNA, 5 days); PNA, individual PNA; Q, intercompartmental clearance; RSE, relative standard error; V1, central volume of distribution; V2, volume of distribution of the peripheral compartment; WT, actual bodyweight (median WT=1000 g); WT, individual WT. the plasma concentration in the youngest age group (PNA day 1) decreases very slowly after the initial distribution phase for all GA groups. Twenty-four hours after bolus administration, the predicted concentration is $0.10,0.088$ and $0.083 \mu \mathrm{g} / \mathrm{L}$ for a GA of 25, 28 and 31 weeks, respectively. At a PNA of 10 days the concentration decreases considerably faster. The plasma concentrations 24 hours after the fentanyl bolus are 0.028 , 0.015 and $0.011 \mu \mathrm{g} / \mathrm{L}$ for a GA of 25,28 and 31 weeks, respectively (figure $3 \mathrm{~A}$ ).

When administering a continuous infusion $(1 \mu \mathrm{g} / \mathrm{kg} /$ hour over 10 days), considerable fentanyl accumulation occurs during the first 10 days of life when compared with older PNAs (figure 3B). In addition, infants with a GA of 25 weeks show higher plasma concentrations compared with those born after 28 or 31 weeks of gestation. Stable plasma concentrations were reached after a PNA of approximately 15 days and were $0.98,0.71$ and $0.68 \mu \mathrm{g} / \mathrm{L}$ for a GA of 25, 28 and 31 weeks, respectively (figure 3B).

When aiming for a comparable exposure across the entire gestational and PNA range, reducing the continuous dose by $50 \%$ until PNA day 4, and by $25 \%$ from PNA day 5 to 9 , will reduce the observed high exposure in the early days (figure $3 \mathrm{C}$ ). Only differences as a result of GA can yet be observed, which could be corrected for by additionally reducing the dose by $40 \%$ and $20 \%$ for 25 and 28 weeks' GA compared with 31 weeks (data not shown). For a child born at 25 weeks this would mean that a dose of $1 \mu \mathrm{g} / \mathrm{kg} /$ hour would have to be reduced to $0.3 \mu \mathrm{g} /$ $\mathrm{kg} /$ hour during the first 5 days of life, $0.45 \mu \mathrm{g} / \mathrm{kg} /$ hour during PNA days $6-9$, and $0.6 \mu \mathrm{g} / \mathrm{kg} /$ hour from PNA day 10 onwards. For a child born at 28 weeks, $0.4 \mu \mathrm{g} / \mathrm{kg} /$ hour would be applicable up to PNA day $5,0.6 \mu \mathrm{g} / \mathrm{kg} / \mathrm{hour}$ for PNA days $6-9$ and $0.8 \mu \mathrm{g} /$ $\mathrm{kg} /$ hour from day 10 onwards.

\section{DISCUSSION}

Using opportunistic sampling, we successfully developed a population PK model that describes the maturation of fentanyl PK in preterm neonates born before 32 weeks of gestation. We found a pronounced influence of postnatal and GAs on fentanyl clearance. Clearance $(\mathrm{L} / \mathrm{hour} / \mathrm{kg})$ was threefold and 1.3-fold lower during the first and second weeks of life, respectively, compared with the third week and older. In preterm infants with a GA of 28 and 31 weeks, clearance was respectively 1.4-fold and 1.7-fold higher compared with infants born at 25 weeks of gestation (table 2). 

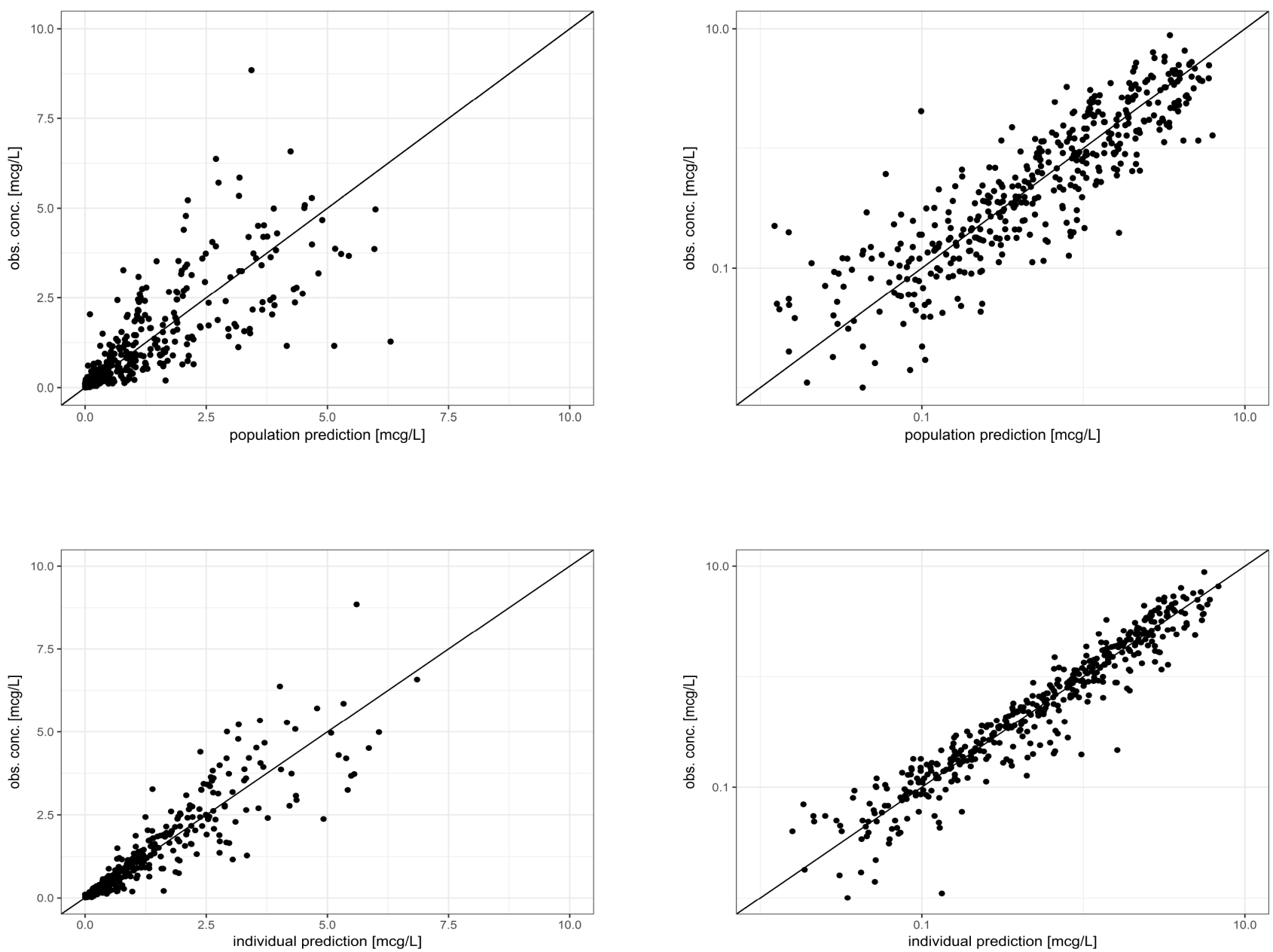

Figure 2 Goodness-of-fit plots, first row: population predicted versus observed values on a linear and on a log scale; second row: individual predicted versus observed values on a linear and a log scale.

These findings are of particular importance because analgesia is very difficult to measure in preterm infants, with a decreased robustness of pain behaviours in the most prematurely born babies in whom pain is most difficult to measure. ${ }^{29}$ As fentanyl is one of the most frequently used analgesics in NICUs, ${ }^{8}$ this study can help gain insight into whether we might overdose or underdose preterm neonates during different stages of maturation.

Previously, Saarenmaa et al described, using a non-compartmental analysis, the PK of fentanyl in term and preterm infants with a median GA of 32 weeks (IQR: 30-36 weeks). ${ }^{11}$ While in our study included neonates with a median gestational of 26.9 weeks, Saarenmaa also found a correlation between clearance and GA, although without reporting an influence of PNA. It therefore seems that the influence of GA is consistent across the entire population of preterm neonates up to term age.

We identified PNA as the most relevant covariate, with very low clearance values at the first days after birth which are rapidly increasing until they stabilise around 10-15 days of life (figures 1B and 3). Similarly, Gauntlett et al found an effect of PNA on clearance in 14 more mature preterm and term infants (PNA: 0-71 days, GA: 32-40 weeks) with clearance stabilising after the first 2 weeks of life. ${ }^{14}$ In addition, they found that when giving a bolus injection to the neonates with the lowest PNA, fentanyl concentration remained rather stable over a long period of time indicating a very low clearance. ${ }^{14}$ We observed the same phenomenon in our study, illustrated by the simulation of a single bolus dose of $2 \mu \mathrm{g} / \mathrm{kg}$ at PNA day 1 (figure $3 \mathrm{~A}$ ).
The developed model suggests that fentanyl clearance is subject to intrauterine and extrauterine maturation as both GA and PNA influenced clearance. This is also supported by the fact that postmenstrual age, combining GA and PNA, did not lead to an equally good model fit as the separate estimation of the two covariates GA and PNA. The observed rapid increase in fentanyl clearance might be related to a significant increase in CYP3A4 activity during the first few weeks of life ${ }^{19}$ alongside an increase in liver blood flow. ${ }^{30} 31$ This increased blood flow is due to the increased portal vein flow and the (slow) closure of the ductus arteriosus. ${ }^{31}$ Thus, although fentanyl clearance is minimally affected by changes in CYP3A4 activity in adults because it is a high extraction ratio drug, ${ }^{32-34}$ CYP3A activity might be of importance in preterm infants. ${ }^{19} 35$

Our model offers the possibility to compare fentanyl exposure of different dosing regimens using simulations. In case of bodyweight-based dosing, for example, a continuous infusion of $1 \mu \mathrm{g} / \mathrm{kg} /$ hour, plasma concentrations during the first days of life will be higher than in older infants (figure $3 \mathrm{~B}$ ) due to very low clearance values (figure 1B). Therefore, undesirably high plasma concentrations will likely be reached in these neonates and an accumulation of the drug is more likely if the drug is administered repeatedly. In a single bolus dose approach, the very low clearance results in a slow terminal decrease of fentanyl in newborns with low PNAs, with $40 \%-50 \%$ of the initial concentration still being present after 24 hours (figure $3 \mathrm{~A}$ ). This might result in a prolonged effect of fentanyl and an increased probability of 
A

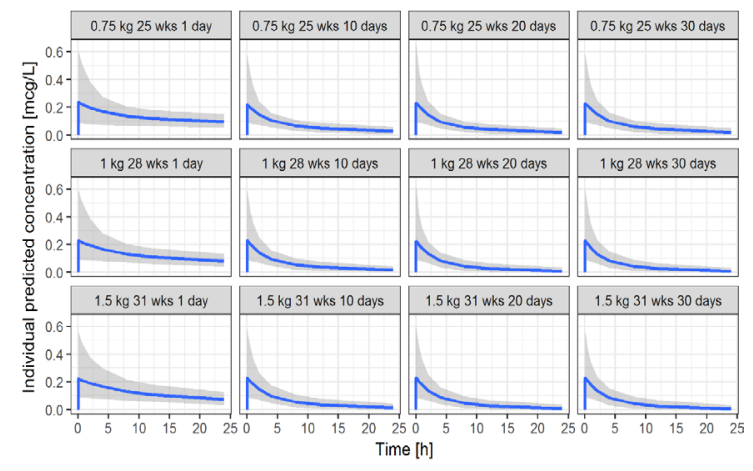

B

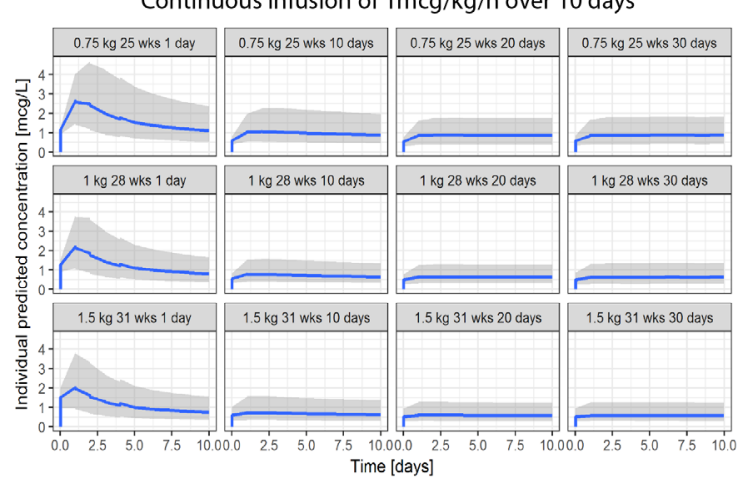

C Continuous infusion $1 \mathrm{mcg} / \mathrm{kg} / \mathrm{h}, 50 \%$ reduction PNA up to 5 days, $25 \%$ reduction for PNA 6-9 days

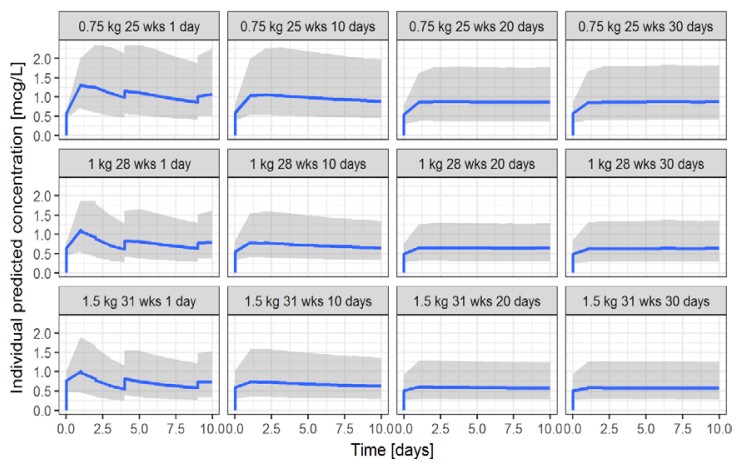

Figure 3 Fentanyl concentration time profiles $(n=1000)$ with blue line representing median and grey shaded areas representing $90 \% \mathrm{Cls}$ for preterm neonates with a birth weight of $0.75,1$ and $1.5 \mathrm{~kg}$ at a postnatal age of 1, 10, 20 and 30 days. (A) A single bolus dose of $2 \mu \mathrm{g} /$ $\mathrm{kg}$ over an observation period of 24 hours. (B) A continuous infusion of $1 \mu \mathrm{g} / \mathrm{kg} / \mathrm{hour}$ given over a period of 10 days. (C) A $50 \%$ reduction in the continuous infusion dose until postnatal age (PNA) day 4, a 25\% reduction in the continuous infusion dose up to PNA day 9, full dose starting at day 10 .

side effects. Furthermore, when administering multiple boluses within the time frame of 24 hours, this low clearance may lead to a considerable drug accumulation in the youngest subjects. One may therefore consider administering lower additional bolus doses in these cases. As can be observed from figure 1, limited data were available for children with PNA above 30 days, especially for children with higher GAs. Due to this, the model might have limited predictive capacity for children older than 30 days in this group.
With the sparse available evidence from literature, ${ }^{8} 36$ it seems difficult to give dosage advices for fentanyl in preterm infants, especially as target concentrations are still lacking. Furthermore, target concentrations might vary between different indications such as acute pain relief during painful procedures or continuous analgesia. ${ }^{837}$ As the blood-brain barrier in preterm neonates differs substantially from that in older children and adults, ${ }^{38-40}$ different concentrations could be present at the site of action during different stages of prematurity and thereby lead to different (side) effects. Opioid receptor ontogeny may further add to this.

In absence of known target concentrations we aimed for comparable exposure across the whole studied age range when simulating potential dosing regimens. Based on this, the maintenance dose of a continuous infusion needs to be reduced for newborns with low PNAs, for example, by $50 \%$ during the first 4 days of life and by $25 \%$ from day 5 to 9 , as simulated in figure $3 \mathrm{C}$. With regard to the PK variability observed in the population, correcting for GA might be less relevant. If a child with a low GA, however, shows signs of oversedation this might give rise to considering a dose reduction due to possibly higher concentrations. A loading dose of two times the maintenance dose from day 10 onwards led to a substantially quicker increase in plasma concentration (data not shown) and might help reach a more immediate effect of the drug. It has to be emphasised that the proposed dose adjustments are based on exposure and have not been externally validated, but that, in the absence of better data on PK and effect, they seem to be an improvement compared with the current uniform bodyweight-based dosing.

\section{CONCLUSION}

Because of the very low clearance during the first days of life, fentanyl dosing based on bodyweight alone does not result in comparable exposure in preterm infants with a GA of 24-32 weeks and a PNA of 1-80 days. Therefore, a single bolus dose in early life will be slowly removed. To prevent accumulation and to reach equal fentanyl exposure during continuous infusion, infusion rates need to be reduced by $25 \%$ and $50 \%$ during days 5-9 and days 0-4, respectively. These results should be considered for clinical practice and when studying the relationship between fentanyl concentration and pain relief in order to distinguish between maturational differences in pain relief and the differences in plasma levels caused by dosing that has not been adjusted for maturational changes.

\section{Author affiliations}

'Division of Pharmacology, Division Systems Pharmacology and Biomedicine, Leiden Academic Centre for Drug Research, Leiden University, Leiden, The Netherlands ${ }^{2}$ Division of Neonatology, Department of Pediatrics, Erasmus MC-Sophia Children's Hospital, University Medical Center Rotterdam, Rotterdam, The Netherlands ${ }^{3}$ Department of Pharmacy, Radboud Institute for Health Sciences, Radboud University Medical Center, Nijmegen, The Netherlands

${ }^{4}$ Department of Pharmacy, Erasmus MC, University Medical Center Rotterdam,

Rotterdam, The Netherlands

${ }^{5}$ Division of Neonatology, Department of Pediatrics, Máxima Medical Center, Veldhoven, The Netherlands

${ }^{6}$ Division of Neonatology, Department of Pediatrics, Erasmus MC-Sophia Children's Hospital, Rotterdam, The Netherlands

${ }^{7}$ Department of Pediatrics, School of Oncology and Developmental Biology, School of Mental Health and Neuroscience, Maastricht University Medical Center, Maastricht, The Netherlands

${ }^{8}$ Division of Neonatology, Department of Pediatrics, Radboudumc, Nijmegen, The Netherlands

${ }^{9}$ Department of Clinical Pharmacy, St Antonius Hospital, Nieuwegein, The Netherlands

Collaborators Dick Tibboel, Monique van Dijk, Ronald de Groot, David Burger, 
Irwin Reiss, Koos Burggraaf.

Contributors SV, RBF: conception and design, analysis, interpretation of data, drafting and revising the manuscript, final approval. PA, LJIZ, KDL: acquisition of data, interpretation of data, revising the manuscript, final approval. KA: interpretation of data, drafting and revising the manuscript, final approval. BCPK: analysis of data, interpretation of data, revising the manuscript, final approval. SHPS, CAJK: conception and design, analysis, interpretation of data, revising the manuscript, final approval.

Funding The DINO study and all accompanying research were funded by the Netherlands Organisation for Health Research and Development ZonMw (grant number: 836011022 )

Competing interests None declared.

Patient consent for publication Not required.

Provenance and peer review Not commissioned; externally peer reviewed.

ORCID iD

Karel Allegaert http://orcid.org/0000-0001-9921-5105

\section{REFERENCES}

1 Carbajal R, Rousset A, Danan C, et al. Epidemiology and treatment of painful procedures in neonates in intensive care units. JAMA 2008;300:60-70.

2 Grunau RE, Holsti L, Peters JW. Long-term consequences of pain in human neonates. Semin Fetal Neonatal Med 2006;11:268-75.

3 Grunau RE. Neonatal pain in very preterm infants: long-term effects on brain, neurodevelopment and pain reactivity. Rambam Maimonides Med J 2013;4:e0025.

4 Smith GC, Gutovich J, Smyser C, et al. Neonatal intensive care unit stress is associated with brain development in preterm infants. Ann Neurol 2011;70:541-9.

5 Aranda JV, Carlo W, Hummel P, et al. Analgesia and sedation during mechanical ventilation in neonates. Clin Ther 2005;27:877-99.

6 Ranger M, Johnston CC, Anand KJ. Current controversies regarding pain assessment in neonates. Semin Perinatol 2007;31:283-8.

7 Thewissen L, Allegaert K. Analgosedation in neonates: do we still need additional tools after 30 years of clinical research? Arch Dis Child Educ Pract Ed 2011;96:112-8.

8 Pacifici GM. Clinical pharmacology of fentanyl in preterm infants. A review. Pediatr Neonatol 2015:56:143-8

9 Guinsburg R, Kopelman BI, Anand KJ, et al. Physiological, hormonal, and behavioral responses to a single fentanyl dose in intubated and ventilated preterm neonates. $J$ Pediatr 1998;132:954-9.

10 Ancora G, Lago P, Garetti E, et al. Efficacy and safety of continuous infusion of fentanyl for pain control in preterm newborns on mechanical ventilation. J Pediatr 2013; 163:645-51.

11 Saarenmaa E, Neuvonen PJ, Fellman V. Gestational age and birth weight effects on plasma clearance of fentanyl in newborn infants. J Pediatr 2000;136:767-70.

12 Wilson AS, Stiller RL, Davis PJ, et al. Fentanyl and alfentanil plasma protein binding in preterm and term neonates. Anesth Analg 1997;84:315-8.

13 Encinas E, Calvo R, Lukas JC, et al. A predictive pharmacokinetic/pharmacodynamic model of fentanyl for analgesia/sedation in neonates based on a semi-physiologic approach. Paediatr Drugs 2013;15:247-57.

14 Gauntlett IS, Fisher DM, Hertzka RE, et al. Pharmacokinetics of fentanyl in neonatal humans and lambs: effects of age. Anesthesiology 1988;69:683-7.

15 Koehntop DE, Rodman JH, Brundage DM, et al. Pharmacokinetics of fentanyl in neonates. Anesth Analg 1986;65:227-32.

16 Labroo RB, Paine MF, Thummel KE, et al. Fentanyl metabolism by human hepatic and intestinal cytochrome P450 3A4: implications for interindividual variability in disposition, efficacy, and drug interactions. Drug Metab Dispos 1997;25:1072-80.

17 Feierman DE, Lasker JM. Metabolism of fentanyl, a synthetic opioid analgesic, by human liver microsomes. Role of CYP3A4. Drug Metab Dispos 1996;24:932-9.
18 Tateishi T, Krivoruk Y, Ueng YF, et al. Identification of human liver cytochrome P-450 $3 \mathrm{~A} 4$ as the enzyme responsible for fentanyl and sufentanil N-dealkylation. Anesth Analg 1996;82:167-72.

19 Lacroix D, Sonnier M, Moncion A, et al. Expression of CYP3A in the human liverevidence that the shift between CYP3A7 and CYP3A4 occurs immediately after birth. Eur J Biochem 1997:247:625-34.

20 Krekels EHJ, van Hasselt JGC, van den Anker JN, et al. Evidence-based drug treatment for special patient populations through model-based approaches. Eur J Pharm Sci 2017;109S:S22-S26.

21 Ince I, de Wildt SN, Tibboel D, et al. Tailor-made drug treatment for children: creation of an infrastructure for data-sharing and population PK-PD modeling. Drug Discov Today 2009:14(5-6):316-20.

22 Brussee JM, Calvier EA, Krekels EH, et al. Children in clinical trials: towards evidencebased pediatric pharmacotherapy using pharmacokinetic-pharmacodynamic modeling Expert Rev Clin Pharmacol 2016;9:1235-44.

23 De Cock RF, Piana C, Krekels EH, et al. The role of population PK-PD modelling in paediatric clinical research. Eur J Clin Pharmacol 2011;67(Suppl 1):5-16.

24 Flint RB, Bahmany S, van der Nagel BCH, et al. Simultaneous quantification of fentanyl, sufentanil, cefazolin, doxapram and keto-doxapram in plasma using liquid chromatography-tandem mass spectrometry. Biomed Chromatogr 2018;32:e4290.

25 Keizer RJ, Karlsson MO, Hooker A. Modeling and simulation workbench for NONMEM: Tutorial on Pirana, PsN, and Xpose. CPT Pharmacometrics Syst Pharmacol 2013;2:e50.

26 Lindbom L, Pihlgren P, Jonsson EN, et al. PsN-Toolkit-a collection of computer intensive statistical methods for non-linear mixed effect modeling using NONMEM. Comput Methods Programs Biomed 2005;79:241-57.

27 Comets E, Brendel K, Mentré F. Computing normalised prediction distribution errors to evaluate nonlinear mixed-effect models: the npde add-on package for R. Comput Methods Programs Biomed 2008;90:154-66.

28 Anchieta LM, Xavier CC, Colosimo EA, et al. Weight of preterm newborns during the first twelve weeks of life. Braz J Med Biol Res 2003;36:761-70.

29 Johnston CC, Stevens BJ, Franck LS, et al. Factors explaining lack of response to heel stick in preterm newborns. J Obstet Gynecol Neonatal Nurs 1999;28:587-94.

30 Grijalva J, Vakili K. Neonatal liver physiology. Semin Pediatr Surg 2013;22:185-9.

31 Gow PJ, Ghabrial H, Smallwood RA, et al. Neonatal hepatic drug elimination. Pharmacol Toxicol 2001;88:3-15

32 Palkama VJ, Neuvonen PJ, Olkkola KT. The CYP 3 A4 inhibitor itraconazole has no effect on the pharmacokinetics of i.v. fentanyl. Br J Anaesth 1998;81:598-600.

33 Ibrahim AE, Feldman J, Karim A, et al. Simultaneous assessment of drug interactions with low- and high-extraction opioids: application to parecoxib effects on the pharmacokinetics and pharmacodynamics of fentanyl and alfentanil. Anesthesiology 2003;98:853-61

34 Ziesenitz VC, König SK, Mahlke NS, et al. Pharmacokinetic interaction of intravenous fentanyl with ketoconazole. J Clin Pharmacol 2015;55:708-17.

35 Abduljalil K, Jamei M, Rostami-Hodjegan A, et al. Changes in individual drugindependent system parameters during virtual paediatric pharmacokinetic trials: introducing time-varying physiology into a paediatric PBPK model. AAPS 2014;16:568-76.

36 Ziesenitz VC, Vaughns JD, Koch G, et al. Correction to: pharmacokinetics of fentanyl and its derivatives in children: a comprehensive review. Clin Pharmacokinet 2018;57:393-417.

37 Meesters NJ, van Dijk M, Knibbe CA, et al. Infants operated on for necrotizing enterocolitis: towards evidence-based pain guidelines. Neonatology 2016;110:190-7

38 Saunders NR, Liddelow SA, Dziegielewska KM. Barrier mechanisms in the developing brain. Front Pharmacol 2012;3:46.

39 Olhager E, Nold-Petry CA, Joshi MS, et al. Preterm lambs given intravenous dopamine show increased dopamine in their cerebrospinal fluid. Acta Paediatr 2014;103:337-42.

40 Ghersi-Egea JF, Saudrais E, Strazielle N. Barriers to drug distribution into the perinatal and postnatal brain. Pharm Res 2018:35:84 